Chirurgia (2019) 114: 352-358

No. 3, May - June

Copyright $\odot$ Celsius

http://dx.doi.org/10.21614/chirurgia.114.3.352

\title{
An Interobserver Agreement Study with a New Classification for Rilb Fractures
}

\author{
Michael Bemelman', Mark van Baal' ${ }^{2}$, Claudia Raaijmakers', Koen Lansink', Luke Leenen², William Long ${ }^{3}$ \\ 'Department of Surgery, Elisabeth-Tweesteden Hospital, Tilburg, The Netherlands \\ 2Department of Surgery, University Medical Center Utrecht, Utrecht, The Netherlands \\ ${ }^{3}$ Department of Surgery, Legacy Emanuel Medical Center, Portland, United States of America
}

Corresponding author:

Mike Bemelman, MD

Orthopedic trauma surgeon

Elisabeth-Tweesteden Hospital

Tilburg, location Elisabeth

Department of Surgery

5022 GC Tilburg, The Netherlands

Phone: +31135393525

Fax: +31135363660

E-mail: m.bemelman@etz.nl

\section{Rezumat}

Studiu clinic prospectiv си о nouă clasificare a fracturilor costale

Context: $\mathrm{Nu}$ există un consens cu privire la indicația pentru stabilizarea chirurgicală a coastelor la pacienții care prezintă fracturi costale. Comparația studiilor este dificilă deoarece nu există un sistem de clasificare al fracturilor la nivel costal. Am introdus primul sistem de clasificare al fracturilor costale, analog sistemului de clasificare AO Müller şi am testat clasificarea printr-un studiu prospectiv.

Metode: Clasificarea are la bază patru caracteristici: identificarea coastei (numărul acesteia), localizarea cranio-caudală, tipul de fractură şi subtipul de fractură. Am demarat un studiu prospectiv folosind această nouă clasificare.

Rezultate: $\mathrm{Au}$ fost analizate douăzeci de investigații CT ale pacienților cu fracturi costale. Patru revizori au clasificat 197 de fracturi costale unilaterale şi bilaterale. Studiul prospectiv a fost substantial [Fleiss $\mathrm{x}=0.62(95 \%$ interval de încredere $0.59-0.65)$ ]. Concluzie: Aceasta este prima clasificare a fracturilor costale la nivel mondial. Studiul prospectiv a fost substanțial. Clasificarea este primul pas în identificarea pacienților care pot beneficia de stabilizarea chirurgicală a coastelor.

Cuvinte cheie: fracturi costale, stabilizarea chirurgicală a coastelor, clasificare, studiu prospectiv 


\begin{abstract}
Background: No consensus exists about the indication for surgical rib fixation in patients with rib fractures. Comparison between studies is difficult since a classification system is lacking for rib fractures. We introduced the first classification system for rib fractures, analogue to the Müller AO classification system and tested the classification with an interobserver agreement study.

Methods: The classification is build up by four characters: the first one describes the rib number, the second character describes the location of the fracture in cranial-caudal fashion, the third character describes the fracture type and the fourth character described the subtype of the fracture. An interobserver agreement study was performed with the new classification.

Results: Twenty CT scans of patients with rib fractures were analyzed. A total of 197 unilateral and bilateral rib fractures were scored by four reviewers. The interobserver agreement was substantial [Fleiss K of $0.62(95 \%$ CI $0.59-0.65)$ ].

Conclusion: This is the first classification for rib fractures worldwide. The interobserver agreement of the classification was substantial. This classification is the first step in identifying patients who would benefit from surgical rib fixation.
\end{abstract}

Key words: rib fracture, surgical rib fixation, classification, interobserver study

\section{Introduction}

Rib fractures are commonly seen after blunt thoracic trauma. Up to $12 \%$ of all fractures diagnosed on the emergency department are rib fractures, especially in the elderly (1-3). Rib fractures are associated with a significant morbidity and mortality, increasing with age, total number of rib fractures and the presence of a flail chest $(4,5)$. Most common complication associated with rib fractures is a pneumonia, which is reported in up to $70 \%$ of patients. Furthermore, the presence of (multiple) rib fractures is associated with mortality rates up to $30 \%(6)$.

The management of rib fractures is focused on pain reduction and optimization of oxygenation and ventilation. With proper pain management adequate respiration and quick mobilization could be achieved, preventing the patient from developing pneumonia. Depending on the severity of the thoracic trauma, some patients need mechanical ventilation due to inadequate respiration, particularly in the presence of a flail chest and accompanied lung contusion.

In the last two decades, surgical rib fixation has been posed as an alternative to the conservative treatment of rib fractures (7). Although surgical rib fixation becomes more and more popular, in literature still no clear consensus exists about the indication for rib fixation (8). In two recent small randomized controlled trials it is suggested that surgical fixation results in reduced pulmonary complications with a lower incidence of pneumonia and shorter need for mechanical ventilation $(9,10)$. Other possible indications are persisting excessive pain despite maximal analgesia, nonunion of fractured ribs and displaced rib fractures. However, it is thought that age and number of rib fractures are the most important prognostic factors for outcome in patients with rib fractures. In accordance to this, recently, a proposed algorithm for surgical rib fixation has been published, suggesting that patients older than 45 years and with the presence of more than four rib fractures might be candidate for surgical rib fixation (11).

Methodological quality of the published studies about surgical rib fixation is moderate, with only two randomized controlled trials and additional retrospective studies $(7,10,11)$. In addition, study groups are very heterogeneous, making comparison even more challenging. In 
clinical practice, classification systems for bone fractures are the basic for fracture treatment and function as a fundament for clinical decision-making. Furthermore a universal classification system makes comparison between studies more straightforward. In 1987, the Müller AO (Arbeitsgemeinschaft für Osteosynthesefragen) classification system was introduced by the AO Foundation as a method of categorizing injuries according to their localization and severity. At present, it is one of the few complete bone fracture classification systems that is widely accepted. However, rib fractures are not included in the Müller AO classification system. Moreover, to our knowledge a rib classification system does not exist at all.

In this study, a new classification system of rib fractures is proposed, based on the Müller AO-classification. Furthermore, we performed an interobserver agreement study to determine the interobserver agreement of the newly introduced classification of rib fractures. The main goal of the proposed classification is primarily to improve communication among physicians and enhance comparison between studies. Ultimately, this classification could play a role in the decision-making between conservative and surgical treatment of rib fractures.

\section{Methods}

\section{Rib Classification System}

The proposed classification of rib fractures is based on the Müller AO classification system. According to this system, the rib fracture classification consists out of four characters: the first two characters describe the location and the third and fourth character describes
Table 1. Location of the rib fracture in the classification system for rib fractures (i.e. second character in a row of four)

\section{LOCATION}

\begin{tabular}{ll}
\hline 1 & Anterior (sternum - anterior axillary line) \\
\hline 2 & Axillary (anterior axillary line - inferior scapula point \\
\hline 3 & Posterior (between both inferior scapula points) \\
\hline$X$ & Overlapping regions \\
\hline
\end{tabular}

the type and subtype of the fracture.

The first character describes the location of the fracture in a cranial-caudal fashion, thus the number of the rib. The second character describes the location of the fracture in an anterior-posterior fashion (Table 1). This location is divided into three regions. A fracture located in the anterior region (i.e. from sternum to anterior axillary line) is associated with a 1. A fracture located in the axillary region is associated with a 2 and covers the region between the anterior axillary line and the line through the inferior scapula point. A fracture located in the posterior region is associated with a 3 and covers the region between both inferior scapula points. If the fracture crosses two regions it is associated with an X.

The third and fourth character describes the fracture type and subtype (Table 2). A nondisplaced fracture is associated with an A. Subsequently, A1 describes a simple transverse or greenstick-like fracture, A2 describes a simple oblique fracture and A3 describes a butterfly fragment. A displaced fracture, with a displacement of more than $2 \mathrm{~mm}$, is associated with a B. Subsequently, B1 describes a transverse fracture, B2 describes an oblique fracture and B3 describes a butterfly fragment. A comminuted fracture is associated with a C. Subsequently, C1 describes a fracture with a comminuted zone of less than $2 \mathrm{~cm}, \mathrm{C} 2$

Table 2. Type and subtype of the rib fracture (i.e. third and fourth character in a row of four)

\begin{tabular}{lll}
\hline & TYPE and SUBTYPE & \\
\hline A. Non-dislocated $(<2 \mathrm{~mm})$ & B. Dislocated $(>2 \mathrm{~mm})$ & C. Comminuted \\
1. Transverse / greenstick & 1. Transverse & 1. Zone $<2 \mathrm{~cm}$ \\
2. Oblique & 2. Oblique & 2. Zone $>2 \mathrm{~cm}$ \\
3. Butterfly fragment & 3. Butterfly fragment & 3. Flail fragment (s) \\
\hline
\end{tabular}



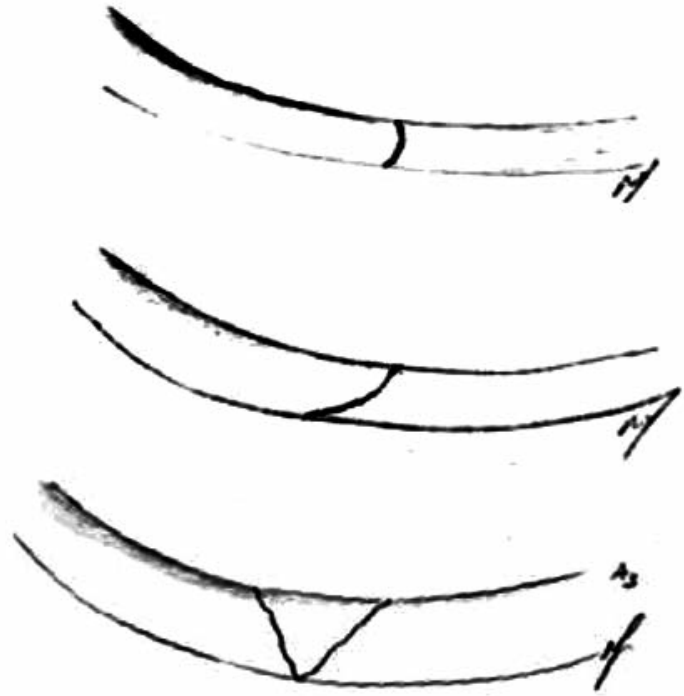

Figure 1. Non-dislocated rib fractures (type A) and all three subtypes

describes a fracture with a comminuted zone of more than $2 \mathrm{~cm}$ and $\mathrm{C} 3$ describes a segmental fracture with two or more fracture in the same rib. Figures 1, 2 and 3 schematically show the different types of rib fractures according to the new classification.

\section{Interobserver Agreement Study}

Twenty anonymized Computed Tomography scans (CT scans) from two clinics (Legacy Emanuel Medical Center, Portland, USA and Elisabeth-Tweesteden Hospital, Tilburg, The Netherlands) were selected and randomly distributed on DVD. The CT scans contained radiological images of patients with multiple unilateral and bilateral rib fractures and were carefully selected in a way that all possible fracture types and subtypes of the proposed classification were present on the DVD. All CT scans were presented in an axial, coronal and sagittal reconstruction. We chose not to show the three-dimensional reconstruction, since this reconstruction could smoothen out fracture lines of the ribs.

Four independent orthopedic trauma surgeons with expertise in thoracic trauma and rib fixation were asked to classify each rib of the
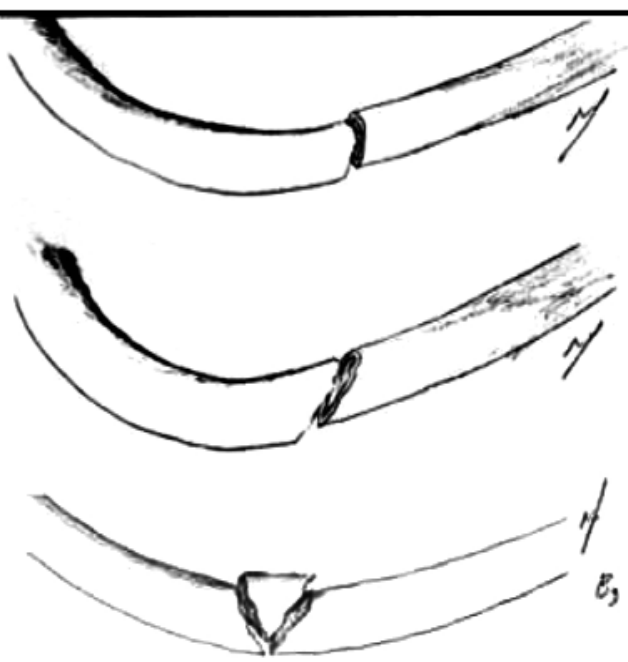

Figure 2. Dislocated rib fractures (type B) and all three subtypes
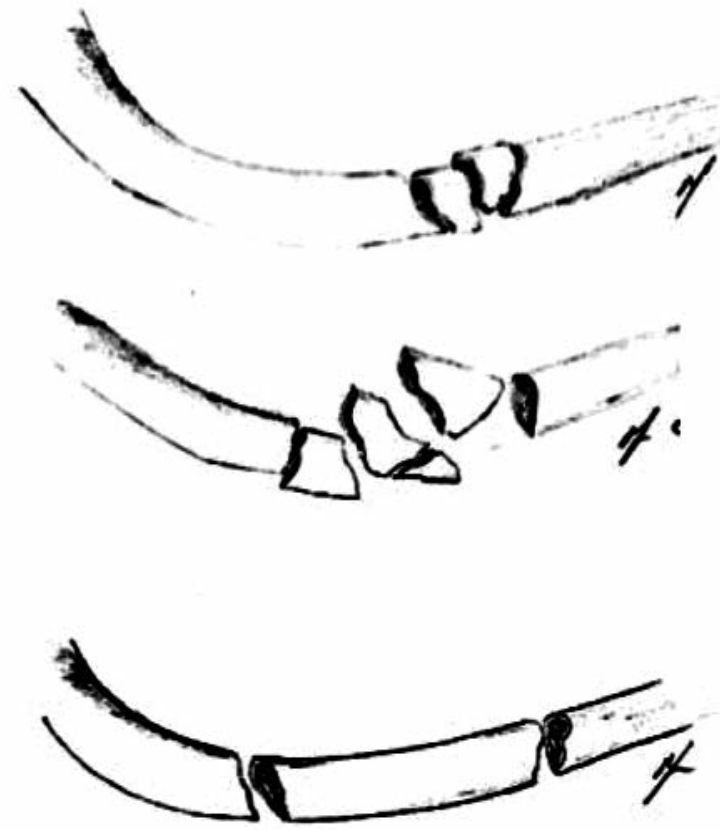

Figure 3. Comminuted rib fractures (type C) and all three subtypes

twenty anonymized CT scans on a standardized form. First, the reviewers were given time to study a sheet with the proposed rib fracture classification. Then, the standardized form and use of the software was explained. The 
reviewers were able to ask additional questions before starting the review of the CT scans. During the scoring process, no interpersonal contact was allowed. The investigator was not present when the scoring process occurred, but was available for additional questions.

Observer data were analyzed and expressed in terms of interobserver agreement. Calculation was done using Fleiss' $\mathrm{x}$ statistics. Fleiss' $\mathrm{x}$ calculates the agreement between a fixed number of observers when assigning categorical ratings to a number of items or classifying items (12). We interpreted the multirater $\kappa$ statistics as follows: values of 0.01-0.20 indicate slight agreement; $0.21-0.40$, fair agreement; 0.41-0.60, moderate agreement; 0.61-0.80, substantial agreement; and $>0.80$, good agreement (13). The Fleiss' $\mathrm{k}$ calculator was taken from an open-access Microsoft Excel spreadsheet. Calculations were performed using 95\% confidence intervals (CI's) (14).

\section{Results}

Twenty CT scans of twenty different anonymized patients were scored by the four reviewers. Thirteen patients suffered from bilateral rib fractures, whereas seven patients suffered from unilateral rib fractures. A total number of 173 fractured ribs were scored by the reviewers, 87 ribs on the left side of the thorax and 86 ribs on the right side. Totally, 76/173 ribs $(44 \%)$ were fractured in two or more places. According to the classification, every possible type of rib fracture was present within the 173 fractured ribs.

Interobserver agreement of the full classification was substantial with a Fleiss $\kappa$ of 0.62 (95\% CI $0.59-0.65)$ for the full classification model. Looking only at the basic A B and C classification there was a slightly higher but also substantial interobserver agreement with a Fleiss $\kappa$ of 0.66 (95\% CI $0.62-0.71)$.

\section{Discussion}

The current study presents the first rib fracture classification worldwide, based on the Müller AO classification. Furthermore we have shown a substantial interobserver agreement with this classification. The proposed classification will enhance comparison between future studies and might help in identifying patients who will benefit from surgical rib fixation.

As mentioned above, the proposed rib classification system is not a clear answer to the question what the exact indication is for surgical rib fixation. Most published literature about surgical rib fixation consists of relatively small studies $(7,10,11)$. Although the number of rib fractures is frequently documented, almost no data about fracture type is reported. One could imagine that outcome in terms of length of hospital stay, admittance to the Intensive Care Unit and the need of mechanical ventilation will be much better in patients with surgically fixated greenstick-type fractures than in patients with fixated flail chests and accompanying pulmonary contusion. Therefore, we feel that there is an urgent need for uniformity when reporting about rib fractures and surgical rib fixation. The current study will enhance scientifically communication about rib fractures, resulting in better comparison of outcomes between studies. Subsequently, patient groups could be identified who might benefit from surgical rib fixation.

The rib classification was designed analogue to the Müller AO classification. The first two characters of the rib classification indicate the location of the rib fracture and the last two characters indicate the fracture type and subtype. We chose this format since the Müller AO classification has been extensively validated in recent years and is broadly incorporated in daily care in trauma orthopedics. However, as the Müller AO classification system, the rib classification is very detailed with the different subtypes of fractures (i.e. the fourth character of the scoring system). It has to be proven whether this comprehensive classification is of clinical importance or that only the fracture types without the subtypes (i.e. only the first three characters) are relevant for daily care.

The twenty CT scans used for the interobserver agreement study were reconstructed in an axial, coronal and sagittal manner. Nowadays, creation of three-dimensional 
reconstructions is fairly simple. Although a three-dimensional reconstruction provides the reviewer a quick overview of all ribs and could function as guidance throughout a heavily injured thorax, we chose not to incorporate this reconstruction. When creating a threedimensional reconstruction, fracture lines could erase and as a consequence, non-dislocated rib fractures could be missed. However, with the substantial interobserver agreement in this study, we think that a three-dimensional reconstruction would not have been of added value for our experienced orthopedic trauma surgeons.

Although surgical rib fixation for patients with a flail chest is more and more accepted worldwide, other indications for surgery are still under debate (8). Potential indications are inadequate analgesia despite maximal conservative treatment and (severe) dislocations of ribs, with or without thorax deformity. All fractured ribs of patients with one of these three (potential) indications for rib fixation could be scored with the proposed classification system. Another potential indication for surgical fixation is the presence of a symptomatic pseudoarthrosis of a rib fracture. However it is not possible to score this type of fracture with our classification system, as no character for pseudoarthrosis was included. A pseudoarthrosis is a different type of fracture with another behavior than the "fresh" rib fractures. Furthermore, little is known about the best treatment of pseudoarthrosis of rib fractures, although a recent study showed that patients with pseudoarthrosis would benefit from rib fixation (15). Because of the different entity of a pseudoarthrosis we chose not to incorporate and score this different entity in the classification system.

The current study has some limitations. First, only four reviewers were included in the interobserver agreement study. All were orthopedic trauma surgeons with expertise in the field of thoracic trauma and rib fixation, no radiologists participated in the study. Parallel to daily care, only the treating physician classifies fractures according to a classification system, not a radiologist. Therefore we chose not to ask radiologists to participate. However, in future another interobserver agreement study could be performed with more reviewers, including radiologists and non-experts in the field of rib fixation. Second, only 20 CT scans were scored by the observers. Although this is a relatively small number, a total of 173 fractured ribs were classified with the new classification. The current study shows that the new classification could be easily used in every patient with rib fractures. However, because of the relatively small number of $\mathrm{CT}$ scans, no conclusions about validity could be made. Therefore, future studies on this classification should be performed with more CTscans and fractured ribs, and, as mentioned before, more observers. Third, the proposed classification system is not an answer to which patient should undergo surgical rib fixation. The system will make scientific communication about the treatment of rib fractures more transparent. We think that with the classification system as a fundament, the first step in identifying the patient who benefits from surgical rib fixation has been made.

\section{Conclusion}

In conclusion, we proposed a classification system for rib fractures analogue to the Müller AO classification system. Rib fractures are classified based on location and fracture type and subtype. An interobserver agreement study with four experts in the field of thoracic trauma and rib fixation showed a substantial agreement between the observers. This classification is not an answer to the question what the correct indication for surgical rib fixation is, but should be seen as a first step to answer this question in the near future.

\section{Conflict of Interest}

No conflicts of interest exist for each author.

\section{References}

1. Bulger EM, Arneson MA, Mock CN, Jurkovich GJ. Rib fractures in the elderly. J Trauma. 2000;48(6):1040-6; discussion 1046-7. 
2. Ziegler DW, Agarwal NN. The morbidity and mortality of rib fractures. J Trauma. 1994;37(6):975-9.

3. Lin FC, Li RY, Tung YW, Jeng KC, Tsai SC. Morbidity, mortality, associated injuries, and management of traumatic rib fractures. J Chin Med Assoc. 2016;79(6):329-34.

4. Cannon RM, Smith JW, Franklin GA, Harbrecht BG, Miller FB, Richardson JD. Flail chest injury: are we making any progress? Am Surg. 2012;78(4):398-402.

5. Dehghan N, de Mestral C, McKee MD, Schemitsch EH, Nathens A. Flail chest injuries: a review of outcomes and treatment practices from the National Trauma Data Bank. J Trauma Acute Care Surg. 2014; 76(2):462-8.

6. Sirmali M, Türüt H, Topçu S, Gülhan E, Yazici U, Kaya S, et al. A comprehensive analysis of traumatic rib fractures: morbidity, mortality and management. Eur J Cardiothorac Surg. 2003; 24(1):133-8.

7. Bemelman M, Poeze M, Blokhuis TJ, Leenen LP. Historic overview of treatment techniques for rib fractures and flail chest. Eur $\mathrm{J}$ Trauma Emerg Surg. 2010 0ct;36(5):407-15.

8. de Jong MB1, Kokke MC, Hietbrink F, Leenen LP. Surgical management of rib fractures: strategies and literature review. Scand J Surg. 2014; 103(2):120-125.
9. Tanaka H, Yukioka T, Yamaguti Y, Shimizu S, Goto H, Matsuda H, et al. Surgical stabilization of internal pneumatic stabilization?: a prospective randomized study of management of severe flail chest patients. J Trauma. 2002; 52(4):727-32; discussion 732.

10. Granetzny A, Abd El-Aal M, Emam E, Shalaby A, Boseila A. Surgical versus conservative treatment of flail chest: evaluation of the pulmonary status. Interact Cardiovasc Thorac Surg. 2005;4(6): 583-7.

11. Bemelman M, de Kruijf MW, van Baal M, Leenen L. Rib Fractures: To Fix or Not to Fix? An Evidence-Based Algorithm. Korean J Thorac Cardiovasc Surg. 2017;50(4):229-234

12. Fleis $\mathrm{JL}$. Measuring nominal scale agreement among many raters. Psychol Bull 1971;76:378-382.

13. Landis JR, Koch GG. The measurement of observer agreement for categorical data. Biometrics 1977;33:159-174.

14. King JE. Resource page: Generalized Kappa \& Orther Indices of Interrater Reliability. 2007. Available at: www.ccitonline.org/jking/ homepage/interrater.html. Accessed April 5, 2018.

15. De Jong MB, Houwert RM, van Heerde S, de Steenwinkel M, Hietbrink F, Leenen LPH. Surgical treatment of rib fracture nonunion: A single center experience. Injury. 2018;49(3): 599-603. 